\title{
Best practices for use of stable isotope mixing models in food-web studies
}

\author{
Donald L. Phillips, Richard Inger, Stuart Bearhop, Andrew L. Jackson, Jonathan W. Moore, \\ Andrew C. Parnell, Brice X. Semmens, and Eric J. Ward
}

\begin{abstract}
Stable isotope mixing models are increasingly used to quantify consumer diets, but may be misused and misinterpreted. We address major challenges to their effective application. Mixing models have increased rapidly in sophistication. Current models estimate probability distributions of source contributions, have user-friendly interfaces, and incorporate complexities such as variability in isotope signatures, discrimination factors, hierarchical variance structure, covariates, and concentration dependence. For proper implementation of mixing models, we offer the following suggestions. First, mixing models can only be as good as the study and data. Studies should have clear questions, be informed by knowledge of the system, and have strong sampling designs to effectively characterize isotope variability of consumers and resources on proper spatio-temporal scales. Second, studies should use models appropriate for the question and recognize their assumptions and limitations. Decisions about source grouping or incorporation of concentration dependence can influence results. Third, studies should be careful about interpretation of model outputs. Mixing models generally estimate proportions of assimilated resources with substantial uncertainty distributions. Last, common sense, such as graphing data before analyzing, is essential to maximize usefulness of these tools. We hope these suggestions for effective implementation of stable isotope mixing models will aid continued development and application of this field.
\end{abstract}

Key words: consumers, diet, food chain, isotopic ratios, trophic level.

Résumé : Si les modèles de mélange d'isotopes stables sont de plus en plus utilisés pour quantifier les régimes alimentaires des consommateurs, ils pourraient être mal utilisés ou mal interprétés. Nous nous penchons sur d'importants défis associés à leur application efficace. La complexité des modèles de mélange a augmenté rapidement. Les modèles actuels estiment les distributions de probabilités des contributions de différentes sources, ont des interfaces conviviales et intègrent des éléments complexes comme la variabilité des signatures isotopiques, des facteurs de discrimination, la structure de variance hiérarchique, les covariables et la dépendance à la concentration. Nous formulons les suggestions suivantes pour assurer la bonne utilisation de ces modèles de mélange. Premièrement, la qualité des modèles de mélange est limitée par celle de l'étude et des données sous-jacentes. Pour permettre la caractérisation efficace de la variabilité isotopique des consommateurs et des ressources à des échelles spatiotemporelles adéquates, les études doivent poser des questions claires et reposer sur une bonne connaissance du système et une conception soigneuse de l'échantillonnage. Deuxièmement, les études doivent utiliser des modèles adaptés à la question posée et tenir compte des hypothèses sous-jacentes et des limites de ces modèles. Les décisions concernant le regroupement de sources ou l'inclusion de la dépendance à la concentration peuvent influencer les résultats. Troisièmement, la prudence est de mise dans l'interprétation des sorties des modèles. Les modèles de mélange estiment généralement les proportions de ressources assimilées avec d'importantes distributions d'incertitude. Finalement, il est nécessaire de faire preuve de bon sens, par exemple en affichant graphiquement les données préalablement à leur analyse, pour maximiser l'utilité de ces outils. Nous espérons que ces suggestions pour une application efficace des modèles de mélange d'isotopes stables contribueront à leur développement et à leur application continus. [Traduit par la Rédaction]

Mots-clés : consommateurs, régime alimentaire, chaîne alimentaire, rapports isotopiques, niveau trophique.

\section{Introduction}

In recent years, stable isotope analysis has become an increasingly important tool in the study of food webs (McKechnie 2004; Crawford et al. 2008). A common application is to use the stable isotopic composition of consumers and their foods to make inferences about the composition of the animal's assimilated diet. This is accomplished by the use of isotopic mixing models to convert the isotopic data into estimates of food source contributions from

Received 8 May 2014. Accepted 12 August 2014.

D.L. Phillips. U.S. Environmental Protection Agency, National Health and Environmental Effects Research Laboratory, Western Ecology Division, 200 SW 35th Street, Corvallis, OR 97330, USA.

R. Inger and S. Bearhop.* Environment and Sustainability Institute, School of Biosciences, University of Exeter, Cornwall Campus, Penryn, Cornwall, TR10 9EZ, UK.

A.L. Jackson.* Department of Zoology, School of Natural Sciences, Trinity College Dublin, Dublin 2, Ireland.

J.W. Moore.* Department of Biological Sciences, Simon Fraser University, Burnaby, BC V5A 1S6, Canada.

A.C. Parnell.* School of Mathematical Sciences (Statistics), Complex and Adaptive Systems Laboratory, University College Dublin, Dublin 4, Ireland.

B.X. Semmens.* Scripps Institution of Oceanography, University of California - San Diego, San Diego, CA 92093, USA.

E.J. Ward.* Northwest Fisheries Science Center, National Marine Fisheries Service, National Oceanic and Atmospheric Administration, Seattle, WA 98112, USA.

Corresponding author: Donald L. Phillips (e-mail: phillips.donald@epa.gov).

*The last six authors contributed equally and are listed in alphabetical order in the list of authors above. 
Fig. 1. Number of citations per year from 1990 to 2012 for papers matching the search terms (a) "stable isotopes" and "mixing model" or (b) "stable isotopes" and "mixing models" from ISI Web of Knowledge. Search conducted June 2013.

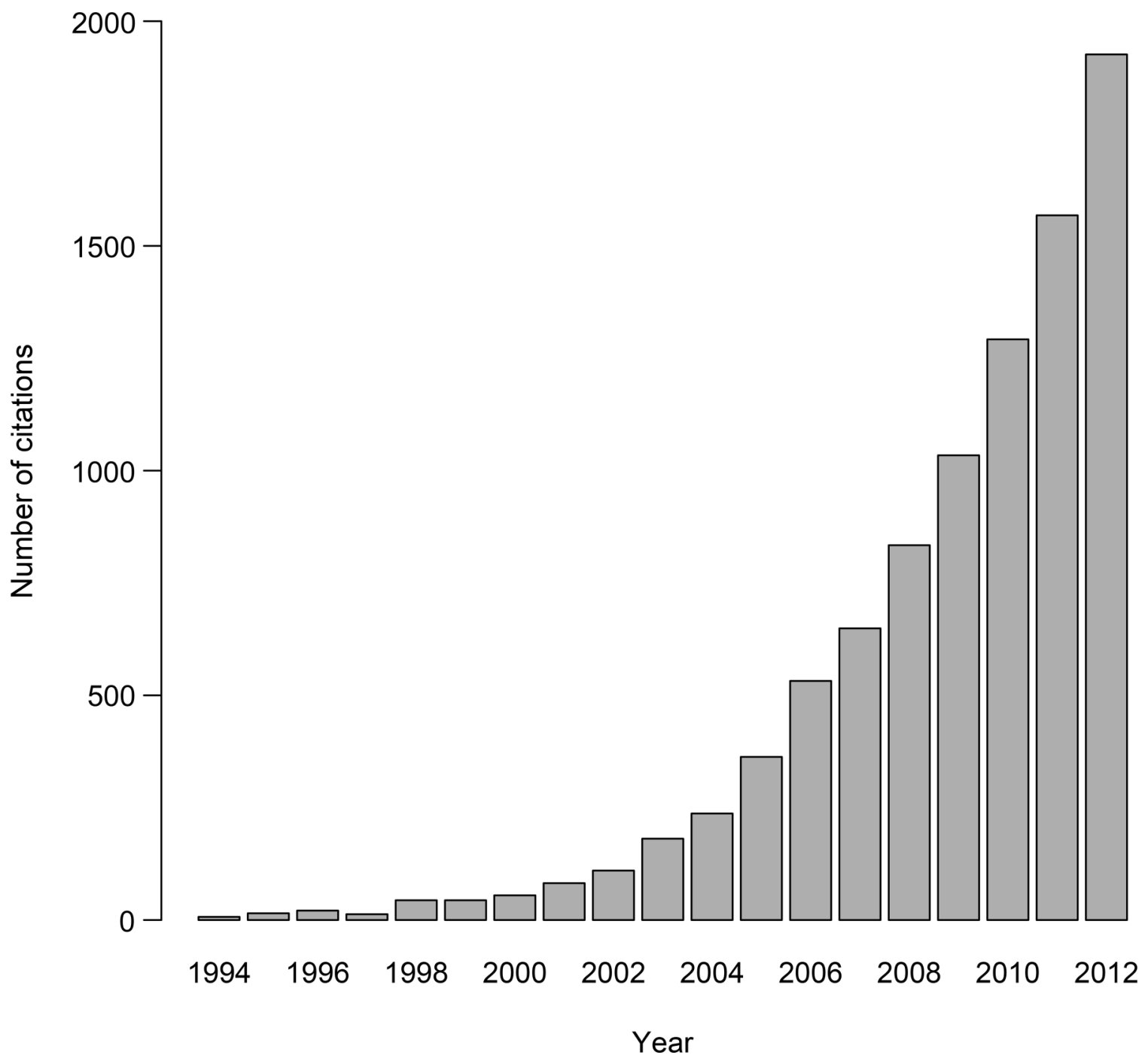

the various components of an animal's diet (Phillips 2012). One of the earliest studies employing this method was Evelyn Haines' classic work on the relative importance of the $\mathrm{C}_{4}$ marsh grass Spartina alterniflora Loisel. (smooth cordgrass) and other $\mathrm{C}_{3}$ plants for Atlantic fiddler crabs (Uca pugnax (S.I. Smith, 1870)) in a Georgia salt marsh (Haines 1976). Since that time, there has been a steady increase in the number of studies utilizing isotopic mixing models to examine animal trophic relations, with a noticeable acceleration in their use in recent years (Fig. 1).

At the same time, mixing model capabilities and sophistication have continued to progress in recent years. Initially, mixing models only provided point estimates for dietary contributions (e.g., $40 \% \mathrm{~A}, 33 \% \mathrm{~B}$, and $27 \% \mathrm{C}$ ), with no uncertainty levels specified to account for variability in consumer or food isotopic values, measurement error, etc. Sources of variation and uncertainty were first explicitly addressed in the IsoError mixing model (Phillips and Gregg 2001a, 2001b). In certain cases, large differences in elemental concentrations among food sources may need to be considered in estimating dietary composition. This feature was incorporated in concentration-dependent equations in the IsoConc model (Phillips and Koch 2002). Traditionally, mixing models could only partition the dietary proportions of two or three food sources based on the use of one or two isotopic values (e.g., $\delta^{13} \mathrm{C}, \delta^{15} \mathrm{~N}$ ), respectively; otherwise the models were mathematically underdetermined and there was no unique solution (Phillips and Gregg 2003). The IsoSource mixing model (Phillips and Gregg 2003) was developed to allow calculation of distributions of possible diets, including a larger number of sources, and has been widely used. Several other similar mixing models using different algorithms were subsequently developed as well (SOURCE/STEP: Lubetkin and Simenstad 2004; MoorePenrose pseudoinverse: Hall-Aspland et al. 2005; LP_Tracer: Bugalho et al. 2008) but have been less frequently used (Layman et al. 2012).

More recently, Bayesian mixing models have been developed that allow flexible model specification in a rigorous Bayesian statistical framework to incorporate some or all of these featuresuncertainties, concentration dependence, larger numbers of sources-as well as others. These models include MixSIR (Moore and Semmens 2008; Ward et al. 2010), SIAR (Parnell et al. 2010), MixSIAR (Stock and Semmens 2013), IsotopeR (Hopkins and Ferguson 2012), and FRUITS (Fernandes et al. 2014). Erhardt and Bedrick (2013) also recently published a description for an unnamed Bayesian mixing model that is an extension of the earlier SISUS model (http://statacumen.com/sisus/, accessed 23 July 2014), and Kadoya et al. (2012) developed IsoWeb, which solves for diet proportions for entire food webs rather than just a focal consumer. Bayesian approaches use statistical distributions to characterize the uncertainties in food source and consumer isotopic values and in estimated source contributions. Alternative linear 
programming approaches use ranges of isotopic values to determine ranges of source contributions even in underdetermined situations (Evrard et al. 2010, 2012). Our focus here is on general principles and practices for use of mixing models in food-web studies; we do not attempt to comprehensively review all the features and capabilities of various individual mixing models here, but Hopkins and Ferguson (2012) provide a table that addresses many of these. Readers are also referred to the papers cited above and review papers that address this topic (Boecklen et al. 2011; Layman et al. 2012; Phillips 2012; Parnell et al. 2013).

With the availability of these tools, the number of isotopic mixing model applications to food-web problems has proliferated in the published literature. Hopefully, there have been gains in our knowledge about food webs and animal diets as a result. However, as with any tools, the best results come when they are the right ones for the job, they are used properly, and their limitations are understood. As the developers of a number of the mixing models cited above, collectively we have had considerable opportunity to see the details of how the models are applied in food-web studies and we consult on those uses when asked. The purpose of this paper is to put forth some "best practices" guidelines for judicious use of isotopic mixing models in these types of studies in the hope that they will help researchers maximize the models' usefulness, but be cognizant of their limitations and assumptions as well.

\section{Suggested guidelines}

\section{Use prior knowledge to identify questions and spatial or temporal scales}

Clearly defined questions or sets of hypotheses should always be the starting point for any well-designed study. Often isotopic mixing models are employed to address general questions such as "what is the diet of consumer X"? However, as discussed more thoroughly in later sections, it must be realized that (i) there is an inherent temporal scale to this question that depends on the choice of samples and (ii) the diet estimates are not precise due to a number of uncertainties. Beyond static estimates of diet for a given time window, interesting questions may be posed about quantifying dietary variation owing to factors such as temporal, spatial, and demographic segregation within or between populations. There may be population hierarchical structures that are either categorical (e.g., different regional populations, different social groups in the same region) or continuous (e.g., differences in zooplankton diet across gradients of light penetration in lakes), and which could either be eliminated from the sampling design or incorporated into the model framework (Semmens et al. 2009). The mixing model technique is particularly powerful when the results of dietary studies are used in subsequent analysis to address questions about causes and consequences of the observed patterns, and determine how diet links to life-history parameters of individuals or dynamics of populations.

Researchers should also consider whether isotopic mixing models are the right tool for the job. While in some systems isotopic analysis can provide unique opportunities and insights, it may not always be the appropriate choice. Examples of this might include the following: (i) where there is little isotopic variation among various food sources; (ii) where the isotopic composition of specific diet items varies substantially on spatial scales over which the consumers move; or (iii) where there is large temporal variation either in diet composition or in isotopic values of diet items relative to the integration time of the consumer tissues sampled. A sound appreciation of the assumptions and limitations of stable isotope analysis and the application of mixing models is key here. Novel study systems where very little is known about dietary preferences are unlikely to be suitable for stable isotopic mixing models, unless there are well-described isotopic gradients across which the consumer is thought to forage such as the gradient between marine and terrestrial habitats. Stable isotope analyses may still be useful for characterizing food-web components and giving a rough idea of trophic levels, for example, but not necessarily for using mixing models to quantify diets of specific consumers with so little background information.

\section{Consider what is known about the animal's diet}

A good understanding of your study system is essential before using stable isotope mixing models to determine the diet of consumers. Isotopic mixing models are not a "magic bullet" and researchers cannot simply sample an animal's tissue, measure the isotopic ratios, and hope to determine its diet. This is because you need to know some aspects of an animal's diet a priori; specifically, you need to know what different food sources might be in the diet of your study species. Identification of food sources may be achieved by traditional means such as direct observation, stomach content analysis, fecal pellet analysis, or via the literature, although we advise caution with the latter approach as recent stable isotope studies suggest that there is considerable inter- and intra-population variability in diet (Votier et al. 2003; Semmens et al. 2009; Willson et al. 2010a; Layman et al. 2012). Once the dietary sources have been identified, stable isotope mixing models offer an excellent way to quantify the diet (in proportional terms) of both individuals and populations and offer significant advantages over other methods. Stable isotope analyses provide a picture of diet integrated over a period of time, while conventional dietary analysis by stomach contents, regurgitates, and fecal pellets give only a short-term picture of diet; in addition, stable isotopes represent assimilated diet rather than what is ingested, which may or may not be digested and contribute to a consumer's nutrition (Bearhop et al. 1999; Votier et al. 2003). Conventional methods may also be biased toward particular types of prey (Hobson et al. 1994).

Microbial food sources can be particularly challenging to discern and characterize, especially in aquatic systems. While allochthonous organic matter may be consumed directly by consumers, it may also be consumed indirectly through microbes that decompose this material. Isotopic characterization of microbial food sources is difficult and is often done indirectly using primary consumers or other proxies (e.g., bulk or size classes of organic matter, respired $\mathrm{CO}_{2}$ ), or compound-specific isotope analysis of biomarkers, although all of these approaches have their own drawbacks; for further discussion of these issues see Middelburg (2014).

\section{Sample collection}

A considered and well-planned sampling design is critical to any stable isotope mixing model study. A critical consideration is the time period over which the diet is to be estimated and what tissues best reflect this period. Bone collagen or fish otoliths may provide dietary information that spans the entire life of an individual (Radtke et al. 1996; Dalerum and Angerbjörn 2005), while other more metabolically active tissues may turn over in days (e.g., liver) or months (e.g., muscle) (Tieszen et al. 1983). Sampling of some tissues (e.g., bone) requires that the consumer is sacrificed. Destructive sampling also has the advantage that any tissue(s) of interest can be sampled. However, while it may be an option for harvested populations (e.g., fisheries or game birds), it is often not feasible due to the nature of the study question, where the aim of the research is to identify how diet affects other parameters in the future, or on moral, ethical, or conservation grounds. Where destructive sampling is not an option (or undesirable), there are a number of nondestructive options available. Blood is a particularly useful metabolically active tissue because it can be separated into two components: plasma, which rapidly turns over and so reflects diet over the previous few days (depending on the study species metabolic rate), and red blood cells, which turn over more slowly and represent diet over the previous few weeks. Hence, a single sample can yield details on diet over two temporal time periods, which may be particularly useful in determining 
diet switches (Hobson and Clark 1993; Votier et al. 2003; Phillips and Eldridge 2006; Klaassen et al. 2010; Heady and Moore 2013). Tissues that are metabolically inert after formation such as hair, claw, or feather also offer scope for constructing time series.

In addition to the isotopic values of consumers, mixing models require data on the food sources consumed. These data are of equal importance to the consumer data and equal consideration and planning should be attached to collection of food sources as well as to the sampling of consumers. There are two key points to consider here: firstly the number of sources to include in the model, and if necessary how to aggregate sources, and secondly temporal and geographic variation in sources.

The number of sources to be included in the model is an initial and critical consideration and will of course be shaped by the study system. Mixing models are sensitive to missing sources and may produce erroneous results if all sources are not included; hence, it is critical that all food sources are sampled (see section 6 below). However, the discriminatory power of mixing models generally decreases with the number of sources, although this is also strongly influenced by the isotopic separation of sources. The number of sources therefore should be kept as low as possible without excluding sources. In our experience, the discriminatory power of mixing models starts to decline markedly above six or seven sources. But how exactly do we define a food source? We will consider a study examining the diet of Brent Geese (Branta bernicla (L., 1758)) (Inger et al. 2006), which alter their diet during the nonbreeding period from feeding almost exclusively on intertidal marine resources during the early season before increasing feeding on terrestrial grasses as the season progresses. During the intertidal foraging period, the birds feed on two species of the seagrass genus Zostera L. (eelgrass (Zostera marina L.) and dwarf eelgrass (Zostera noltii Hornem.)), and as this becomes depleted, they eat increasing amounts of the green algae Ulva lactuca (L., 1753) and various species of the genus Enteromorpha Link, 1820 (= Ulva L., 1753) before moving inland to feed on terrestrial grasses, which are dominated by perennial rye grass (Lolium perenne L.) and common timothy (Phleum pratense L.). So we can identify at least six sources, although this number would increase if we tried to identify Enteromorpha to species level and include all the different species of terrestrial plants on which the geese feed. Aggregation of isotopically similar sources is one way to reconcile the competing needs for including all utilized sources but retain discriminatory power. For the Brent Goose system, the isotopic data for each species of food revealed clear patterns leading to the aggregation of the samples into four sources by combining the different species of Zostera, Enteromorpha, U. lactuca, and terrestrial grasses because these groups were clearly clustered and separated in isotopic space (Fig. 1 in Inger et al. 2006). In addition, these source groupings make intuitive sense biologically and were pertinent to the study question. (For further discussion of source aggregation see section 7 below.)

If mixing models are used to analyze diet variation in a hierarchical population structure, data collection must assess the isotopic composition of sources across these strata. The isotopic values of sources may vary widely both temporally and spatially, so it is also important to ensure that the samples taken for analysis geographically match the food the consumers are eating and reflect the time periods over which the tissues of interest were synthesised, which is likely to mean that source samples are collected before those of the consumer. Temporal matching of sources and consumers can be particularly problematic for tissues that integrate over longer terms, such as bone collagen, as the isotopic ratios of these tissues represent the average of all food sources consumed and any diet switches that may have occurred during the period of synthesis. There may also be considerable isotopic variation within sources even from the same geographic and temporally sampled population and it is important that the sampling regime adequately captures this variation.
When using Bayesian mixing models that fully incorporate sources of uncertainty, the amount of data collected for both consumers and sources can have a substantial impact on the precision of model-based parameter estimates. Bayesian models use means and variances (and, for more advanced models, covariances) supplied by the user to characterize uncertainty for each source. However, traditional model formulations assume that these means and variances are known without error, while in reality they are estimated from samples. When the number of samples per source is small $(<20)$, there may be considerable uncertainty in the mean and variance values, and Ward et al. (2010) recommend a "fully Bayesian approach" that models them as random variables conditioned on the observed sample data. When using hierarchical models to incorporate structure in a modelling framework (e.g., subpopulations, social groups, individual differences in consumers; Semmens et al. 2009), the number of samples within each level of the model can have substantial influence on the precision of the level-specific variance terms. Limitations of time and expense often limit the number of samples that are possible to collect and analyze, so there are trade-offs among sample size, model complexity (number of parameters to estimate), and the precision of estimation.

\section{Use appropriate diet-tissue discrimination factors}

The saying "you are what you eat plus a few per mil" (DeNiro and Epstein 1976) refers to the fact that even at isotopic equilibrium with its diet, an animal's tissues generally have somewhat higher (usually) isotopic values for $\mathrm{C}$ and $\mathrm{N}$ than its diet because of discrimination during assimilation and excretion processes (Olive et al. 2003). Before applying a mixing model, these systematic differences must be corrected. This is generally done either by subtracting a diet-tissue discrimination factor (DTDF) from the consumer tissue isotope values or adding it to the food source isotope values. The latter approach is more flexible, allowing different factors for different food sources (Ben-David et al. 1997b). Whereas most studies focus on the dietary contributions of prey items directly consumed, some studies aim instead to measure the importance to the consumer of food webs based on different basal resources (generally producers or detritus). One example of this is the study of Reid et al. (2008) on the importance of biofilm, allochthonous detritus, macrophytes, and algae basal resources for stream consumers. This requires additional information about trophic structure, as the DTDFs must be multiplied by the number of trophic levels between the consumer and the basal resources to appropriately correct the isotope values used in the mixing model analyses.

Early studies indicated that DTDFs were around $+1 \%$ for $C$ (DeNiro and Epstein 1978), +3\% for N (DeNiro and Epstein 1981), and negligible for S (Peterson and Fry 1987). More recently, researchers have documented considerable variation in DTDFs. Several review and meta-analysis papers (McCutchan et al. 2003; Vanderklift and Ponsard 2003; Dalerum and Angerbjörn 2005) summarized this variation as a function of a number of environmental and physiological factors that include environment (terrestrial, freshwater, marine), trophic level, taxon, tissue, metabolic rate (poikilotherm, homeotherm), nitrogenous excretion (ammonia, urea, uric acid), and sample treatment procedures. Other authors have examined the effects of diet quality on trophic enrichment (Webb et al. 1998; Adams and Sterner 2000; Robbins et al. 2005; Miron et al. 2006; Florin et al. 2011). Caut et al. (2008b, 2009) proposed that DTDFs vary systematically based on the isotopic values of the diet, but this conclusion has been criticized for the lack of a theoretical and mechanistic basis and also because of mathematical artefacts and experimental biases (Auerswald et al. 2010; Perga and Grey 2010; Codron et al. 2012). Because of the multiplicity of factors that can affect DTDFs, this is probably one of the biggest sources of uncertainty in using mixing models to assess diet, and DTDF estimates obtained for the particular situation (e.g., taxon, tissue, diet) 
Fig. 2. Sample $\delta^{15} \mathrm{~N}$ vs. $\delta^{13} \mathrm{C}$ biplot of a consumer (MINK) and its food sources corrected for trophic enrichment. For simplicity, only mean values are shown here. The dotted lines show the minimum bounding rectangle that corresponds to the lowest and highest food source values for $\delta^{15} \mathrm{~N}$ and $\delta^{13} \mathrm{C}$. The solid lines show the convex hull defined by the sources. Note that shrimp is not a vertex of the convex polygon created because its inclusion as a vertex would create a concave side. The consumer must fall inside this mixing polygon for its isotopic composition to be explained as a mixture of just these seven food sources. Data are from Ben-David et al. (1997b).

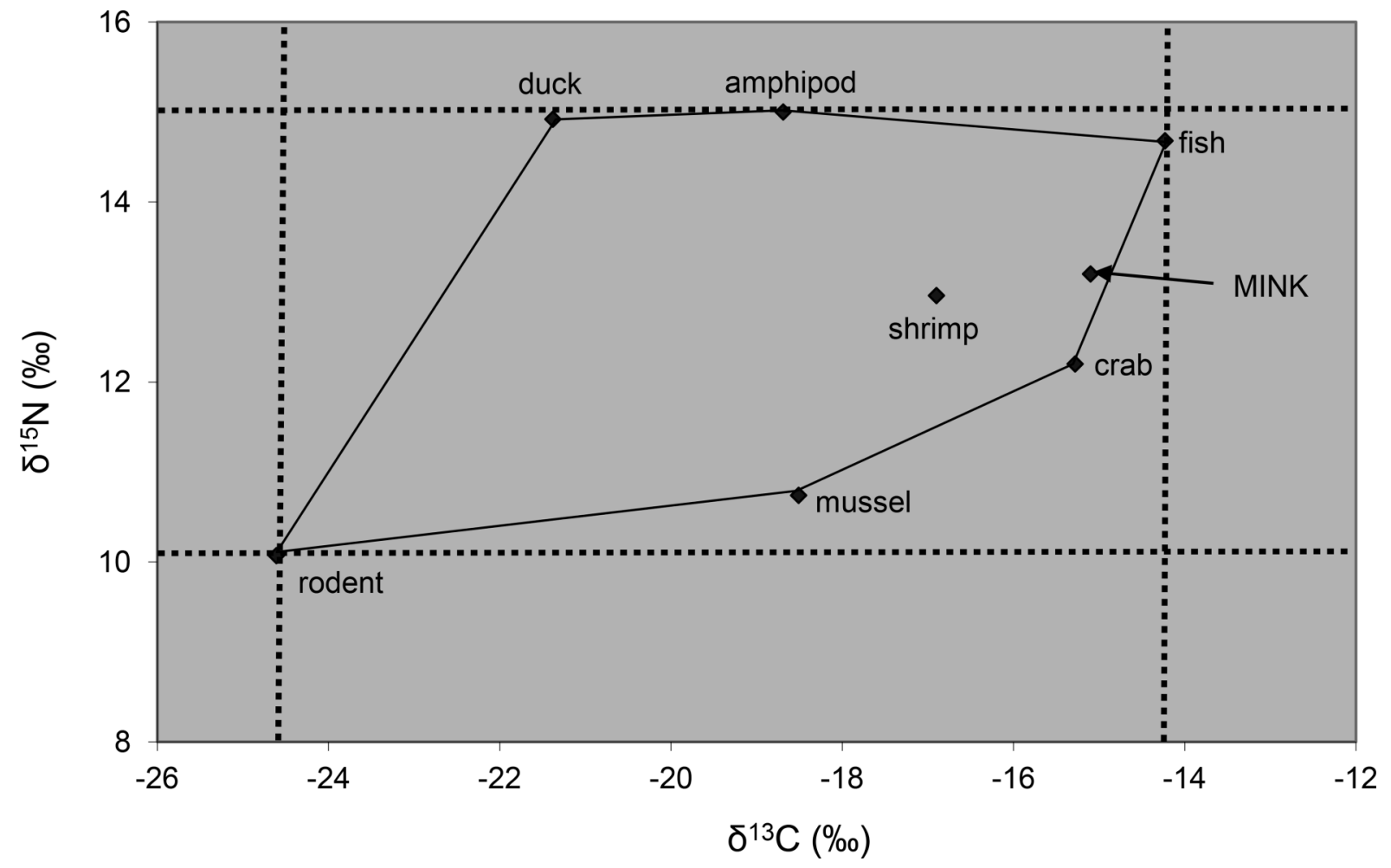

are likely to produce the most accurate results (Spence and Rosenheim 2005; Caut et al. 2008a; Bond and Diamond 2011). Particularly useful in this regard are captive feeding studies (DeNiro and Epstein 1978, 1981; Tieszen et al. 1983; Hobson and Clark 1992; Hilderbrand et al. 1996) and studies of wild populations where their diets are well-known (Fox-Dobbs et al. 2007; Harper 2007; Newsome et al. 2010). It should be clear, however, that in the vast majority of cases there will always be some uncertainty and variability associated with the DTDFs. This was one of the rationales behind the production of Bayesian mixing models such as MixSIR (Moore and Semmens 2008) and SIAR (Parnell et al. 2010). These models have the advantage of allowing one to specify a priori a standard deviation around the DTDF estimate to account for this uncertainty in the mixing analysis. Despite incorporating this uncertainty because DTDFs are one of the key parameters in mixing models, it is not surprising that results are still sensitive to the values used for DTDFs. We strongly recommend the use of sensitivity analysis to test the robustness of model outputs to variation in DTDFs.

\section{Plot your data}

It is always a good idea to do some exploratory data analysis to make sure that you understand the data that you will be processing with a mixing model. After applying appropriate DTDF corrections (see section 4), the first thing that should be done is to plot the data. If, for example, one has $\delta^{13} \mathrm{C}$ and $\delta^{15} \mathrm{~N}$ values for consumer tissues and for various food sources, then plot those on a graph of $\delta^{15} \mathrm{~N}$ vs. $\delta^{13} \mathrm{C}$ or vice versa (Fig. 2). Food source isotopic values can be plotted as mean values, along with confidence intervals around those values if desired. Consumer values can be plotted similarly, or isotopic values for individual consumers may be shown. In order for there to be solutions for diet composition from these food sources, the consumer isotopic values must fall within the range of the food source isotopic values. For example, if the consumer had a $\delta^{15} \mathrm{~N}$ value of $16 \%$ but all its food sources ranged from $10 \%$ o to $15 \%$ (after correction for DTDFs), then there is no combination of those food isotopic values that could result in the observed consumer isotopic value. While there technically could be mathematical solutions that involve negative diet proportions and possibly proportions $>100 \%$, these make no physical or biological sense and should not be considered, as assumed by current mixing model applications.

Thus, consumer isotopic values within the range of corrected food source isotopic values for each element (e.g., C and N) is a necessary condition for mixing models to work. This is illustrated by a bounding rectangle in the $\delta^{15} \mathrm{~N}$ vs. $\delta^{13} \mathrm{C}$ biplot (Fig. 2). However, this condition is not sufficient because there may be corners of this space that are outside the range of any "combination" of $\delta^{13} \mathrm{C}$ and $\delta^{15} \mathrm{~N}$ values. For example, in Fig. 2 if the mink had a $\delta^{13} \mathrm{C}$ value equivalent to that of the rodent and a $\delta^{15} \mathrm{~N}$ value equivalent to that of the duck, it would fall within the bounding rectangle but there still would be no set of dietary proportions for these seven food sources that could result in the observed isotopic values for the mink. The only way to account for the mink's $\delta^{13} \mathrm{C}$ is for the diet to consist entirely of rodents, but this would not account for the high $\delta^{15} \mathrm{~N}$ value. If two isotopic values are used (e.g., $\delta^{13} \mathrm{C}$ and $\delta^{15} \mathrm{~N}$ ), a useful graphical two-dimensional geometric procedure is to use the food source data points to define a "convex hull". In essence, one connects the food source data points with lines to create a convex polygon with these data points as vertices. If including a source as a vertex would lead to a concave side (e.g., shrimp), then it would not be connected but allowed to just lie inside the convex polygon defined by the other sources (Fig. 2). If the consumer lies within the convex hull in isotope space defined by the food sources, then one or more solutions exist that can 
explain the consumer's isotopic values as a combination of those dietary components. If it does not, then the reason for this must be sought. Are there data transcription errors? Are there other food sources that should have been included? Have DTDF corrections been applied or are their values inappropriate? If mean isotopic values of food sources are used for the vertices but source sample variability is being considered as in Bayesian models, then the question of whether the consumer lies within the convex hull or not becomes fuzzy. Smith et al. (2013) propose a Monte Carlo procedure to construct many possible convex hulls, taking into account the variability in isotopic values and DTDF values. They then calculate the proportion of these hulls that contain the consumer data points and recommend using a mixing model with a particular set of sources only if this proportion is greater than some specified level (e.g., 95\%).

Fry (2013) proposed some graphical procedures for analyzing mixing problems as an alternative to mixing models. These involve subdividing mixing diagrams into zones and using several semiquantitative indices to indicate the relative degree of uncertainty in the source (e.g., dietary component) proportions for mixtures (e.g., consumers) that fall in these areas. It has long been recognized that the geometry of sources and mixtures in a mixing diagram determines how constrained or diffuse the possible source contributions may be (e.g., Fig. 6 in Phillips and Gregg 2003). Fry's (2013) procedures may be useful for getting a qualitative feel for mixture data, but Semmens et al. (2013) were critical of their subjectivity and Fry's dismissal of the statistical probability foundation of Bayesian mixing models.

\section{Include all sources in an informed way}

One of the implicit assumptions of any mixing model is that all the sources are included and researchers should strive to ensure that this is the case to get the most reliable results. If one food source that contributes to the diet is excluded from the analysis, then that necessarily will lead to a bias in the estimates of the dietary contributions for the other sources since they must still sum to $100 \%$. The sum of these biases over the remaining food sources will equal the actual contribution of the excluded source. It may not seem too important if a food source that contributes $5 \%$ to the diet of the consumer is excluded because the remaining food sources will simply be attributed to $100 \%$ of the diet rather than the actual 95\%. However, the magnitude and direction of the biases for the individual food sources may vary greatly depending on the geometry of the mixing space. Figure 3 shows a hypothetical example of four food sources in the diet of a consumer. Source D is the most different from the consumer in its isotopic values and one might be tempted to consider excluding it from the analysis on that basis. Table 1 shows the effect of this exclusion on the results of mixing model analyses for the remaining food sources under different hypothetical diets that are all consistent with the data. Even when the deleted source actually only accounts for $5 \%$ of the diet (diet No. 5), this causes biases of $+10 \%$, $-15 \%$, and $+10 \%$ (which sum to $5 \%$ ) on the dietary proportion estimates for the other three sources. However, in this particular example, it is also possible that source $\mathrm{D}$, which isotopically is the most dissimilar from the consumer, could represent up to $25 \%$ of the diet (diet No. 1); in this case, its deletion would lead to extreme biases of $+50 \%,-75 \%$, and $+50 \%$ (which sum to $25 \%$ ) for the other three sources.

This example was designed as a worst case scenario for demonstrating the potential impact of excluding a source. It may be tempting to drop a source because of its dissimilarity in isotopic composition from the consumer, but that dissimilarity also magnifies the effect on estimates for the other sources. There are obvious limits to including everything as remotely possible food sources from the standpoint of sample collection logistics, expense of stable isotope analyses, and the general broadening of source contribution distributions as the number of sources increases. To the extent possible, researchers should use information from other sources (e.g., fecal analyses, behavioral observations, previous studies) in selecting the food sources for an animal dietary study. Excluding sources should be based on knowledge that they are not important in an animal's diet, not just that they are isotopically dissimilar; this example demonstrates that they may still contribute and exclusion from the model still biases the results. Residual error terms provide one approach to account for this (Parnell et al. 2010, 2013). An alternative to excluding sources to simplify the mixing model is to group sources together, which is the next topic.

\section{Consider grouping sources}

If sources of uncertainty (e.g., sample variability, measurement error, diet-tissue discrimination factor uncertainty) are not considered, then in theory mixing models using $n$ isotope values (e.g., $\delta^{13} \mathrm{C}, \delta^{15} \mathrm{~N}$ ) can be used to find a unique set of assimilated diet proportions for $n+1$ food sources. Models with greater than $n+1$ sources are underdetermined and multiple solutions exist, often leading to diffuse ranges of possible diet proportions for each source (Phillips and Gregg 2003; Moore and Semmens 2008; Parnell et al. 2010). While valid food sources should not be discarded from the model as discussed above, combining some sources to reduce the total number may sometimes lead to more constrained, less diffuse solutions (Phillips et al. 2005) and should be considered to be an option. Phillips et al. (2005) proposed alternative a priori and a posteriori approaches for combining sources, described below.

Gannes et al. (1998) stated that when using stable isotope data to reconstruct animal diets, the sources examined should have isotopically distinct signatures. The a priori approach involves performing statistical tests for equality of means and combining sources before running the mixing model if they are not significantly different (Ben-David et al. 1997a, 1997b). Rosing et al. (1998) provided a K-nearest-neighbor randomization test for this specific purpose, but other statistical tests might be used as well. Interpretation of the results will be more sensible if the sources that are combined are logically related in some way (e.g., same taxon or trophic guild) so that the combined source has some biological meaning (Phillips et al. 2005). If several sources are not significantly different in their isotopic composition, then they may be represented in the mixing model by a single set of isotopic values that is computed as the means of the individual source isotopic values or as weighted means if weighting by sample size is desired. What if several sources are similar in their isotopic values, but are still statistically different? The threshold for significance of differences varies with sample size in statistical tests, and if sample size is large, then a small difference (e.g., a small fraction of $1 \%$ ) may test as significant even though it is of no practical biological significance. Alternatively, the objective may be to contrast general groups of food sources whose isotopic differences are large compared with the variation within the groups (e.g., $C_{3}$ vs. $\mathrm{C}_{4}$ plants, marine vs. terrestrial foods). So some judgement may be applied, but sources should only be combined a priori if they are not significantly different in their isotopic composition using either strict statistical criteria or modifying those by judgments of biological significance if sample sizes are large, or if the within-group isotopic variation is small compared with the amonggroup variation. But combining sources with somewhat larger isotopic differences (e.g., several \%o) implies that the individual sources each contribute equally if simple means are used, or contribute relative to their respective sample sizes if weighted means are used. These implied contributions may not be the case and may lead to biases in the mixing model estimates for some or all of the sources. This concern is not an issue if there is no significant difference among sources because the mean (or weighted mean) isotopic values are common to the sources being combined. Fortin et al. (2007) and Edwards et al. (2011) provide recent examples of 
Fig. 3. Hypothetical mixing diagram for four food sources where one (source D) is deleted from the mixing analysis. The solid lines indicate the mixing polygon without $\mathrm{D}$ and the broken lines indicate how it would be extended by including $\mathrm{D}$. For the effects of deleting source $\mathrm{D}$ on the proportion estimates for the other sources see Table 1.

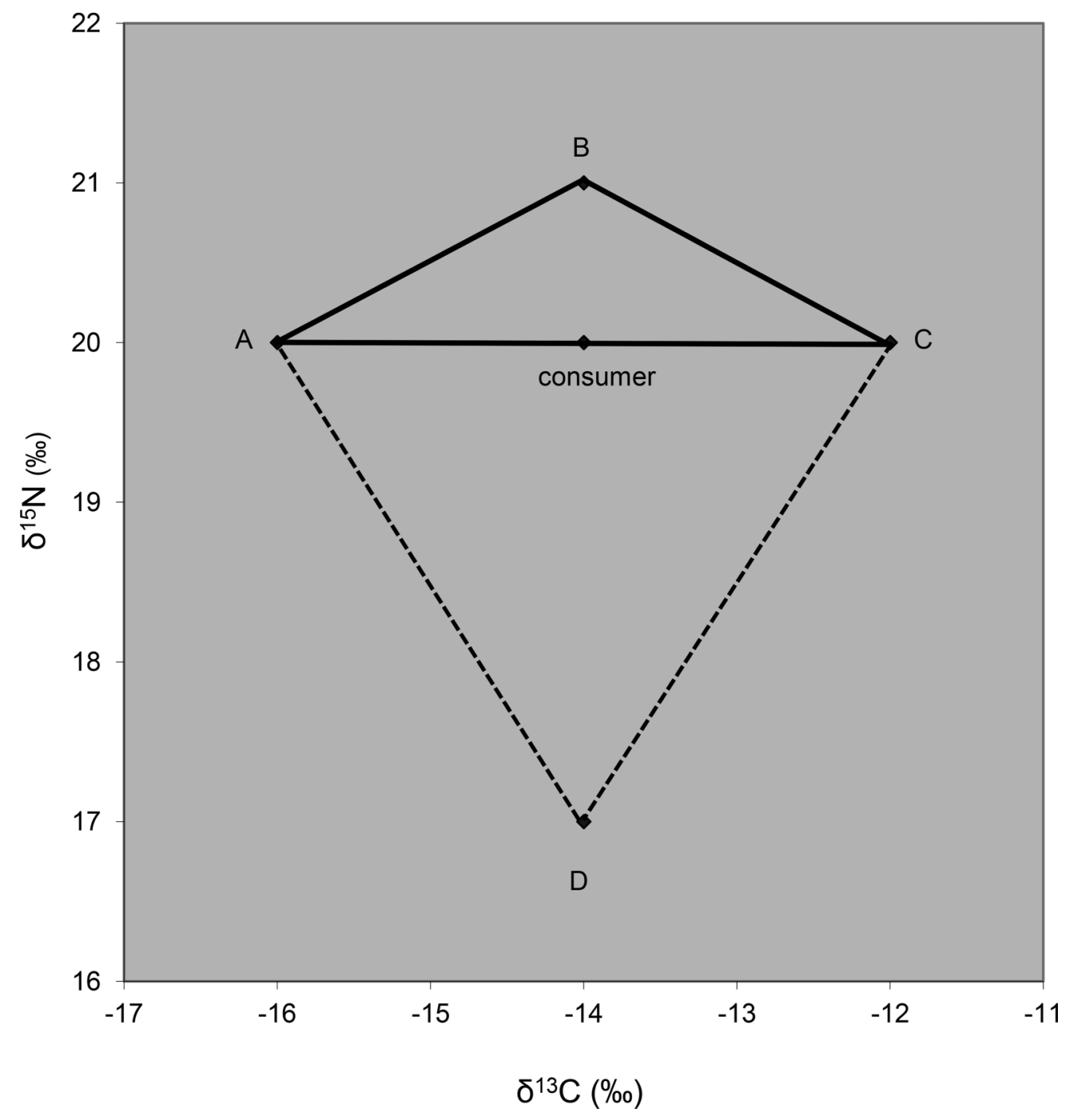

Table 1. Effect of deleting a utilized food source (source D) on the dietary proportion estimates for the remaining food sources (see Fig. 3).

\begin{tabular}{lclllll}
\hline & \multicolumn{2}{l}{ Hypothetical actual diets (\%) } & \\
\cline { 2 - 5 } Food source & Diet 1 & Diet 2 & Diet 3 & Diet 4 & Diet 5 & Mixing model estimate \\
\hline A & 0 & 10 & 20 & 30 & 40 & 50 \\
B & 75 & 60 & 45 & 30 & 15 & 0 \\
C & 0 & 10 & 20 & 30 & 40 & 50 \\
D & 25 & 20 & 15 & 10 & 5 & - \\
\hline
\end{tabular}

Note: Five different hypothetical diets are shown, all of which are consistent with the data. If any one of these represents the actual diet, then the difference between the mixing model estimates and the actual source proportions represent the bias induced by dropping source D out of the model.

this a priori approach to combining sources in their studies of bear diets.

Alternatively, in the a posteriori approach, all the candidate sources may be included in the mixing model, providing the usual distribution of proportions for each source. Then for each individual solution, the proportions can be summed for sources that are to be grouped together (Phillips et al. 2005). Since this approach utilizes each individual solution, it preserves the covariation structure among source proportions. In some cases, especially where there are more than four or five sources, the distribution of pos- sible solutions for each source can be fairly wide and diffuse, while those for combined sources may be much narrower and lead to easier interpretation. Figure 4 shows an example of this from a study of paleohuman diets in northern California from Newsome et al. (2004) and discussed further in Phillips et al. (2005). Three marine food sources with a broad range of $\delta^{13} \mathrm{C}$ and $\delta^{15} \mathrm{~N}$ values were included in the mixing model for Early Holocene humans and had broad distributions of possible dietary contributions: pinnipeds (4\%-48\%), shellfish (0\%-36\%), and marine fish (0\%-68\%). These ranges were so broad that they did not provide 
Fig. 4. Ranges of feasible dietary biomass contributions of individual marine food sources for an early Holocene (about 7000 years ago) group of humans on the central California coast (Newsome et al. 2004). Distributions shown reflect 11345 dietary solutions found by the mixing model. While broad ranges of use are possible for each individual marine food source, the combined marine food group is tightly constrained and represents 70\%-84\% of the diet. (From Phillips et al. 2005, reproduced with permission of Oecologia, vol. 144, p. 524, ( 2005 Springer Science + Business Media.)

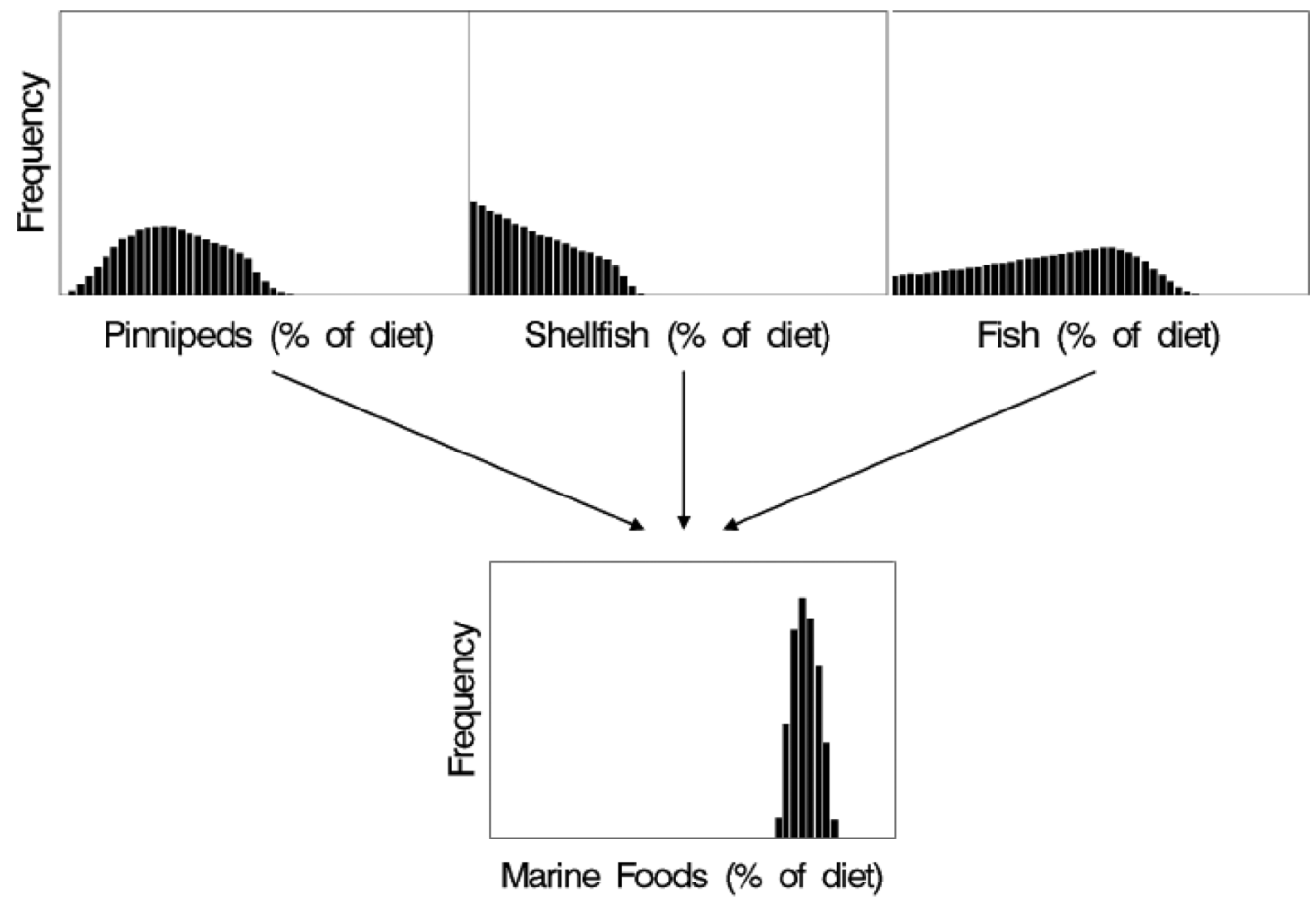

much information at all about diet. However, when these sources were combined a posteriori into a general "marine foods" source, the combined marine source had a dietary contribution range of $70 \%-84 \%$, which clearly indicates the primacy of marine foods versus terrestrial foods in the diet of these humans. Recent examples of this a posteriori approach for combining sources in animal studies include Painter et al. (2009) and MacArthur et al. (2011) using IsoSource, Cherry et al. (2011) using MixSIR, and Vaslet et al. (2011) using SIAR. Ward et al. (2011) proposed a procedure using the MixSIR Bayesian mixing model to evaluate the posterior probabilities of various combinations of sources for the a posteriori approach. Researchers may choose group membership strictly based on maximum posterior probability, or they may weigh the trade-offs between slightly lower posterior probability with greater biological relevance and interpretability (e.g., combining sources with similarities in functional guild, taxon, habitat).

\section{Consider concentration dependence and isotopic routing}

If there are large disparities among food sources in the concentrations of elements associated with the isotopic values being used (e.g., $\mathrm{C}$ for $\delta^{13} \mathrm{C}, \mathrm{N}$ for $\delta^{15} \mathrm{~N}$ ), then the possibility of using a concentration-dependent mixing model might be considered (Phillips and Koch 2002). In a typical mixing model application employing $\delta^{13} \mathrm{C}$ and $\delta^{15} \mathrm{~N}$ values for food sources and consumer tissues, there is an implicit assumption that the proportion of $\mathrm{C}$ that each source contributes to the consumer is the same as the proportion of $\mathrm{N}$ that it contributes. But if $\mathrm{C}$ and $\mathrm{N}$ concentrations vary widely so that the sources have very different $\mathrm{C}: \mathrm{N}$ ratios, then this may be an untenable assumption. This may be particularly applicable to omnivores that consume both low $\mathrm{N}$ (and high $\mathrm{C}: \mathrm{N}$ ) plant foods and high $\mathrm{N}$ (and low C:N) animal foods. A concentrationdependent model allows for different $\mathrm{C}$ contributions, $\mathrm{N}$ contributions, and overall biomass contributions from any food source, depending on elemental concentrations and isotopic values. Readers are referred to Phillips and Koch (2002) for details on how concentrations are incorporated into mixing models. The original IsoConc model (Phillips and Koch 2002) performs these calculations for a two-element three-source system, but concentration dependence has also been incorporated into SIAR (Parnell et al. 2010), IsotopeR (Hopkins and Ferguson 2012), MixSIAR (Stock and Semmens 2013), and FRUITS (Fernandes et al. 2014), which can deal with any numbers of isotopic values and sources. When stable isotope analyses are performed, elemental concentrations are also determined along the way, so researchers should be sure to ask the laboratory for these data to consider concentration dependence.

Since isotopic mixing models assess the proportions of food sources assimilated by the consumer, not just ingested by the consumer, elemental concentrations in the ingested foods may not be the most appropriate measure. Rather, the macromolecular composition (e.g., \% protein, lipid, carbohydrate) and the digestibility and $\mathrm{C}$ and $\mathrm{N}$ concentrations in these macromolecular components will determine the amounts of assimilated $\mathrm{C}$ and $\mathrm{N}$ from each food source; Koch and Phillips (2002) show how these calculations can be made. Thus, the data needs for using a concentration-dependent model in this way are considerably higher and the requisite information may not always be available. On the other hand, after going through all these calculations, it may turn out that the assimilated $\mathrm{C}$ and $\mathrm{N}$ concentrations are much more similar among sources than their raw $\mathrm{C}$ and $\mathrm{N}$ concentrations indicate. A plant food source may have a low $\mathrm{C}: \mathrm{N}$ ratio compared with an animal food source, but when the $C$ in indigestible materials like lignin, cellulose, and fiber are subtracted out, the result may be more similar to the animal food. In this case, the results of a concentration-dependent mixing model would be similar to those of a standard model, although this would not be known a priori without going through these calculations (Koch and Phillips 2002). In other cases, the results for contributions of $\mathrm{C}, \mathrm{N}$, and overall biomass from various food sources to the con- 
sumer's tissues may be quite distinct when sizable source differences in assimilated $\mathrm{C}$ and $\mathrm{N}$ concentrations exist (Phillips and Koch 2002). Gauthier et al. (2003) first applied the concentrationdependent model to examine the use of endogenous vs. exogenous food resources in birds. More recent examples of concentrationdependent mixing model use include applications to mice (Ramírez-Hernández and Herrera M 2010), birds (Rutz et al. 2010), fish (Wilson et al. 2010b; Vaslet et al. 2011), and shellfish (Wilson et al. 2010b; MacArthur et al. 2011).

A major assumption in all aforementioned mixing models is that the food sources are homogenised fully in the consumer where they are reassembled to generate new tissues (Wolf et al. 2009). It is well known that the metabolic pathways for creating new tissues, even within an organism, are physiologically different and hence fractionate heavy and light isotopes differently (Caut et al. 2009; Martínez del Rio et al. 2009; Wolf et al. 2009). Furthermore, food sources that differ considerably in the compounds containing $\mathrm{N}$ and $\mathrm{C}$ are likely to be processed differently within the consumer. This process is readily dealt with by applying appropriate DTDFs for a given consumer tissue and source combination. Where this becomes more difficult is where the diet itself affects the DTDFs so that they become a function of the proportion in which they and the other sources are consumed. This can occur when consumer diets comprise sources with very different balances in protein and carbohydrates such as nectarand fruit-eating animals, and omnivores (Martínez del Rio et al. 2009). In this case, not only can the relative masses of $C$ and $N$ differ between the sources (which can be handled by including concentration dependence in the model), but also consuming low $\mathrm{N}$ or low $\mathrm{C}$ diets can alter the balance between exogenous (dietderived) and endogenous (recycled from other tissues) compounds (Martínez del Rio et al. 2009).

The problem from a statistical modelling point of view is that the functional form describing how fractionation is affected by diet is unknown (Martínez del Rio et al. 2009), and in reality, this will likely differ by species and from case to case. Without any general process to govern how this should behave, at present this means that incorporating this feature may require tailor-made models to be developed based on detailed empirical studies specific to that system. Explicitly separating the amino acids in consumer tissues that have arisen exogenously from those derived endogenously is one promising avenue of study for dealing with this issue in cases where it is suspected a priori of being of importance (Budge et al. 2011). In many cases, however, the diet components of consumers are not so radically different in their composition, so this routing issue is likely to be of less concern.

As a practical matter, how should these issues of possible concentration effects and isotopic routing be handled when the food sources do vary substantially in their composition, e.g., in omnivory? In such cases, we suggest using a concentration-dependent mixing model after correcting for differences in digestibility of food sources and their constituents, unless those corrections indicate that there is little remaining difference in digested elemental concentrations. Where one is concerned that routing is an issue but cannot obtain detailed empirical data on the physiology of diet-affected DTDFs, we would recommend increasing the uncertainty on the DTDFs (see section 4 above). In this manner, one is treating the process as unobservable nuisance and pushing it to an error term, rather than modelling it directly, and the uncertainty of the source contribution estimates will increase accordingly.

\section{Consider and incorporate uncertainties}

Initially, mixing models could only provide point estimates for two or three source proportions as a function of point estimates (means) of one or two isotopic values for both the consumer and its food sources, with no consideration of variability among samples or measurement error. IsoError (Phillips and Gregg 2001a, 2001b) was an early mixing model development that incorporates these factors and provides statistical confidence limits around the proportion estimates. However, this model does not cover underdetermined systems where there were greater than $n+1$ sources when using $n$ isotopic values. IsoSource (Phillips and Gregg 2003) addresses underdetermined systems and provides distributions of possible sets of source proportions, but IsoSource does not include sampling and measurement sources of uncertainty in a straightforward way. Recent Bayesian mixing models such as MixSIR (Moore and Semmens 2008; Ward et al. 2010), SIAR (Parnell et al. 2010), MixSIAR (Stock and Semmens 2013), IsotopeR (Hopkins and Ferguson 2012), FRUITS (Fernandes et al. 2014), and that of Erhardt and Bedrick (2013) explicitly deal with variability among consumer and source isotopic values (which implicitly include measurement errors). Furthermore, these models can incorporate uncertainty in the assigned values of DTDFs as well, which is one of the greatest sources of uncertainty in applying mixing models to food webs (Caut et al. 2008a; Bond and Diamond 2011). While Bond and Diamond (2011) criticized the sensitivity of Bayesian model results to assumed DTDF values for their particular data examples, this reflects the inability of any mixing model to adequately resolve source proportions where the isotopic values are in a narrow range, particularly when that range is of similar magnitude to the uncertainty in DTDF values. The ability to specify uncertainties for DTDFs in Bayesian models at least allows demonstration of the lack of precise solutions possible, which is a more honest result than the more constrained results that would be found by simply relying on a single DTDF point estimate. We urge researchers to use these Bayesian mixing models and take advantage of their ability to incorporate various sources of uncertainty in their estimates of source proportions.

\section{Report distributions of results}

Just as it is important to incorporate sources of variability and uncertainty and not just rely on point estimates in mixing model inputs, researchers should report the distributions of source proportion estimates and not just summary values (e.g., means or medians) in mixing model outputs. As Phillips and Gregg (2003) stated in their concluding sentence, "To avoid misrepresenting the uniqueness of the results, users should report the distribution of feasible solutions rather than focusing on a single value such as the mean." Even when mixing models are not underdetermined, sample variability, measurement error, and uncertainty in DTDF values impart uncertainty in source proportion estimates. Researchers should always strive to provide statistical bounds on these estimates, such as the $95 \%$ confidence intervals provided by IsoError (Phillips and Gregg 2001a, 2001b) and the corresponding 95\% credible intervals (Bayesian confidence intervals) provided by Bayesian models. Outputs from Bayesian models are true probability distributions that may be plotted and summarized with any number of descriptive statistics, as well as compared with each other, with hypothesized distributions, or with other parameters of interest such as fitness (Parnell et al. 2010). Although it is intuitive, making histograms of the estimated source proportions is extremely important-doing so helps identify posteriors that are relatively flat (not informed by data) and situations where posterior sources are multimodal (such as from a data set with two sources that are not identifiable, because they have similar or opposing source signatures).

Many authors fail to consider the impact of joint uncertainty in the source proportions. These are provided in the output of Bayesian models such as MixSIR and SIAR and allow users to spot where the isotopic arrangement of sources leads to unavoidable model inadequacy. In Fig. 5, the matrix plot shows that Enteromorpha and Zostera are strongly negatively correlated. This means that, if Enteromorpha is being consumed at the top of its probability range, then Zostera is likely to be at the bottom of its probability range, and vice versa. Thus, the marginal uncertainty (shown in the histograms) in each source proportion is artificially inflated and no 
Fig. 5. Matrix plot of food sources for the Brent Goose (Branta bernicla) example (discussed in section 3) during their intertidal foraging period. The diagonal cells show the posterior probability distributions for each of the four food sources. The cells below the diagonal show the correlations between contributions for pairs of food sources. The cells above the diagonal show contours of the joint posterior probability distribution for contributions for pairs of food sources.

\section{Matrix plot of proportions}
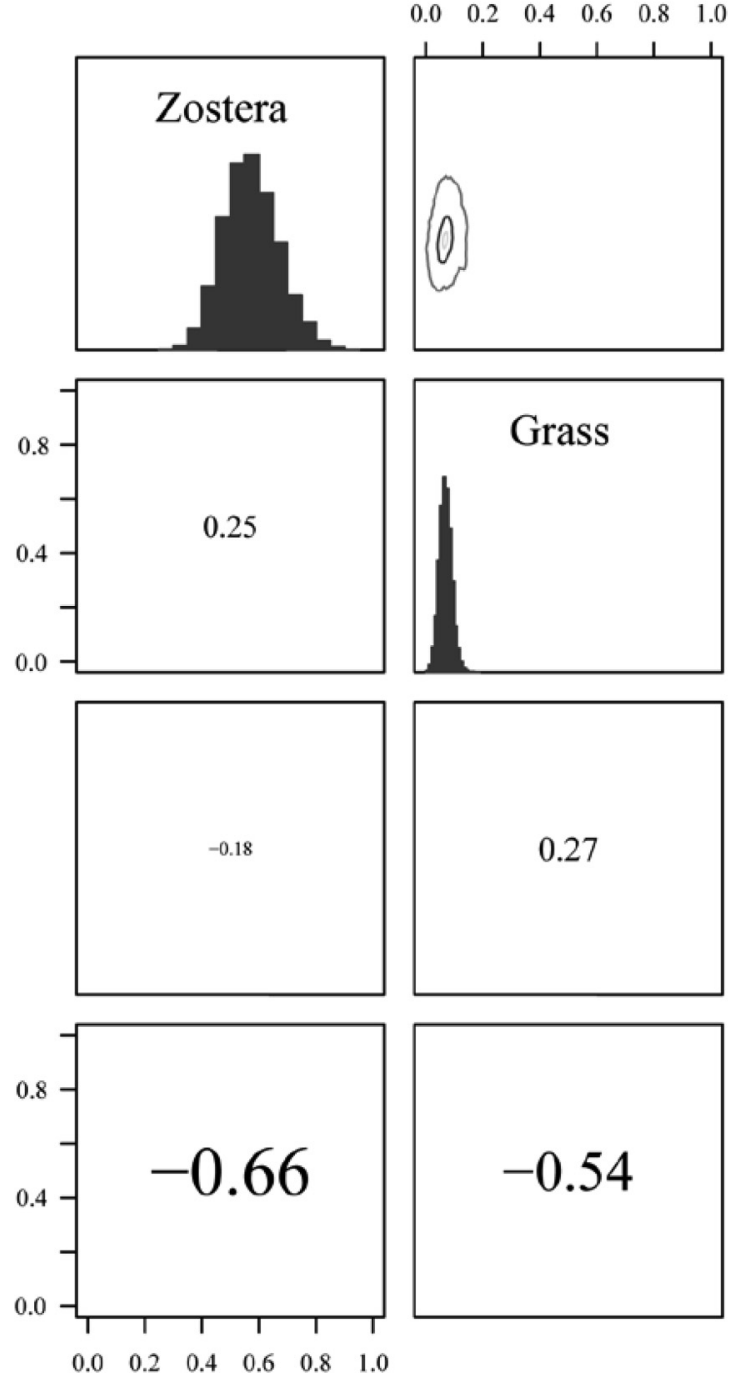

amount of extra data collection could have reduced this uncertainty. If desired, extremely negatively correlated source proportions may be combined (as in the a posteriori manner described above) with a potential gain in precision.

\section{Limitations}

Stable isotope mixing models can be a useful tool for unraveling trophic relationships in food webs and understanding the causes and consequences of variation in diets, but they are just a tool and the picture that they provide of dietary composition is not necessarily a precise one. Common sense dictates that their limitations be recognized. Variability in the isotopic composition of food sources and individual consumers blurs the picture, as does uncertainty in DTDFs. The degree to which nice constrained distributions of source contributions are found depends greatly on the geometry of the mixing space-where the consumer falls within the range of its food sources and how different those food sources are from each other. One cannot expect a precise and unambiguous sorting of the contributions of dietary sources based on isotopic values if they are not fairly distinctive in their isotopic composition.
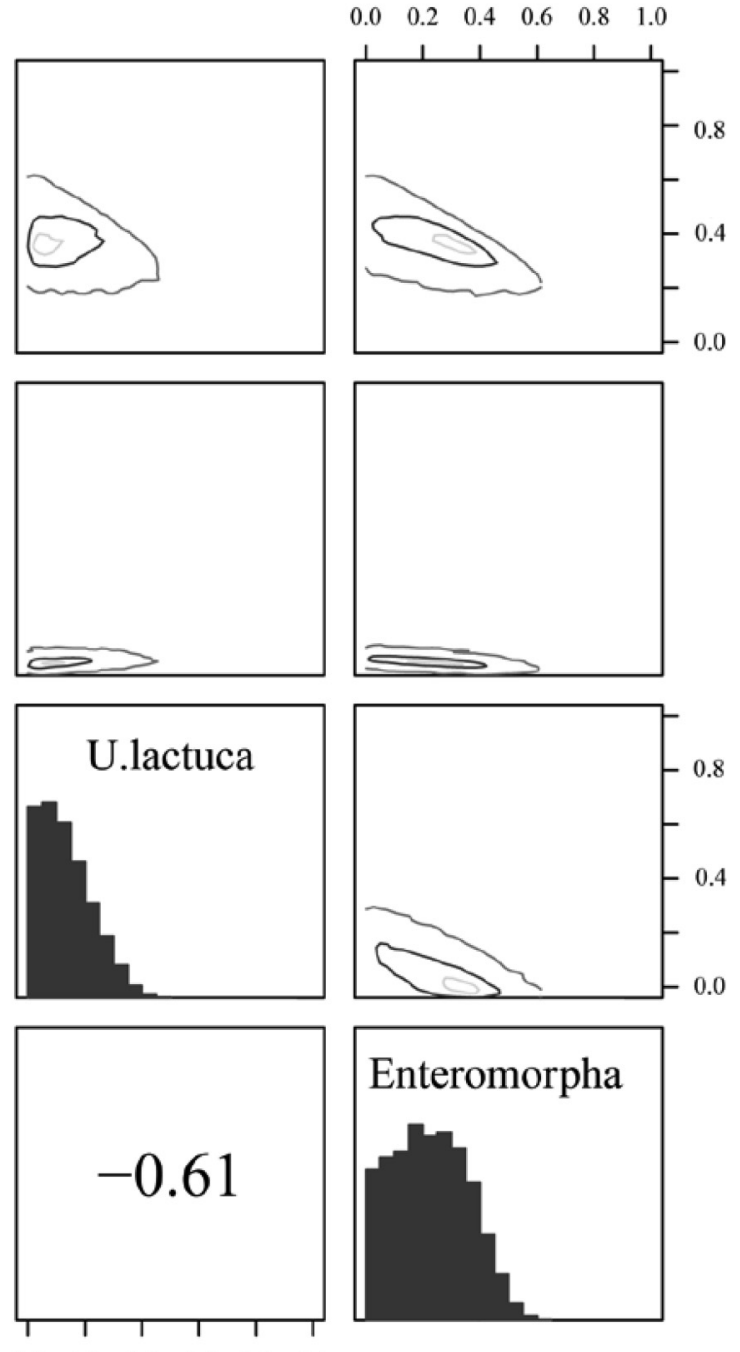

Beyond these sources of uncertainty, however, the degree to which a mixing model is underdetermined (having many more sources than isotopic tracers) is an overarching consideration. This is a fundamental and structural source of uncertainty, as mathematically there are a large number of solutions where the number of variables exceeds the number of constraints. In general, the more food sources there are in an animal's diet, the less precise will be the estimates of their importance. This effect can be magnified by the effects of mixing space geometry as described above. In some cases, the distributions of food source contributions may be so wide that it is only useful in a very qualitative sense, ruling out contributions that are less than the minimum value and more than the maximum value (Fry 2013). For such cases, Benstead et al. (2006) stated that the most useful results are those with low maxima or high minima.

Besides not always providing a very precise determination of dietary importance, mixing models may not necessarily always provide an accurate one if their assumptions are not met. Two of those assumptions are that all sources are included and that there 
is complete mixing. The existence of unsampled sources, concentration differences among sources, and metabolic routing may compromise the validity of the results. The turnover rates of the consumer tissues sampled define the time frame over which the diet is being integrated. Within this time frame, temporal variability in diet, or spatial variability if the consumer shifts locations, make for a "moving target" and may muddle the results, although Francis et al. (2011) modified the Bayesian mixing model framework to account for continuous diet gradients. Similarly, mixing models generally do not consider any differences in prey availability, although several methods have been proposed to incorporate this information to some extent (Phillips et al. 2006; Yeakel et al. 2011). As with simple linear regression, mixing models generally assume that errors are normally distributed. Recent mixing model tools, such as MixSIR and SIAR (Moore and Semmens 2008; Parnell et al. 2010), assume that all consumers have the same diet (more advanced models, like the hierarchical model of Semmens et al. (2009) and Parnell et al. (2013), can explicitly account for individual differences). Finally, the distinction must also be kept in mind that any inferences from mixing models refer to the assimilated diet, which can be considerably different from the ingested diet, depending on the relative digestibility of various foods.

As with many statistical approaches, the fitting of the model to the data creates some further issues of which users should be aware (Parnell et al. 2013). The model fitting algorithm used by SIAR (Parnell et al. 2010), IsotopeR (Hopkins and Ferguson 2012), and Erhardt and Bedrick's (2013) model is called Markov chain Monte Carlo (MCMC) and involves repeatedly guessing values of the dietary proportions, discarding those which are not probabilistically consistent with the data (Parnell et al. 2010). The new guesses are required to be close to the older guesses, creating a Markov chain. At the end of the run, the user is supplied with a sample of posterior dietary proportions, from which they can form means, standard deviations, or any other function they require. An unfortunate side effect of the MCMC algorithm is that it can become stuck and not find suitable high-probability values. For this reason, the posterior sample proportions are checked to see if they "converge" to some suitable stable high-probability values. If this check is not performed, the model may be producing incorrect dietary estimates.

An alternative (but strongly related algorithm) to MCMC used by MixSIR is sampling importance resampling (SIR) (Moore and Semmens 2008). Here, a large number of plausible dietary proportions are chosen and then weighted according to their probabilistic consistency with the data. These weights are rescaled to sum to 1 and the original plausible dietary proportions are resampled according to their weights. The downside to the SIR approach is that if the initial plausible set of dietary proportions does not contain many good values, then there will be very few large weights (also known as a low effective sample size). If this is the case, then the uncertainty in the dietary proportions will be estimated poorly. Both disadvantages (lack of convergence for MCMC, badly distributed weights for SIR) can be easily discerned with suitable checks provided as part of the packages.

\section{New horizons}

A number of advances have been made in stable isotope mixing model methods for food-web studies in recent years, but this is a dynamic field that continues to move ahead. One general area in which we expect further advances is bringing additional nonisotopic constraints to bear in mixing analyses. Earlier work included Phillips et al. (2006), which proposed a general postfiltering procedure for any type of constraints, and Sinisalo et al. (2006), which used intestinal parasite presence to further constrain estimates of the diet of seals. Later work with Bayesian models included Yeakel et al. (2011), which used prey abundance data to weight source estimates in model posterior distributions when sources were isotopically similar, and Chiaradia et al. (2014), which incorporated DNA analysis data into model prior distributions to further constrain dietary estimates. The recent MixSIAR model (Stock and Semmens 2013) allows for incorporation of hierarchical population structure and other continuous covariates in its estimation of consumer diets. Phospholipid-derived fatty acid (PLFA) analyses, compound-specific isotopic analyses, and pulse-chase experiments using enriched isotopic tracers to label certain food-web components are other powerful and promising techniques that are being increasingly used to supplement bulk natural abundance isotopic analyses in food-web studies (Van den Meersche et al. 2009; Evrard et al. 2010, 2012; Middelburg 2014).

The mixing models described in this paper for the most part focus on a single consumer species in a food web based on isotopic composition. In contrast, linear inverse models (Vezina and Platt 1988) attempt to solve matter and energy flows throughout the food web based on an array of estimates of biomass, flux, etc., and other constraints that is generally highly underdetermined. There is potential for some merging of these two approaches to get better estimates of food-web processes utilizing both types of data and some steps have already been taken in this direction. From the mixing model side, Kadoya et al. (2012) have developed the IsoWeb model, which uses stable isotope data along with a userspecified food-web topology to estimate diet proportions for the entire food web. From the linear inverse model side, Eldridge et al. (2005) first incorporated carbon stable isotope data as constraints in an estuarine food-web model. Recently, Pacella et al. (2013) used results from the stable isotope mixing model SIAR as additional constraints input into a linear inverse model of an estuarine food web. These first steps show the potential for synergy between these two different modelling approaches.

\section{Conclusions}

Mixing models can quantify resource contributions to consumers through analysis of stable isotopes. However, they are not the best tool for every job. For instance, many study systems will have source isotope signatures that overlap broadly in isotope space, preventing source discrimination. Some consumers may feed on such a diversity of prey that stable isotopes can only provide a blurry picture of patterns of consumption. On the other hand, stable isotopes may provide insights into consumer-resource relationships that would otherwise be difficult to impossible to quantify. We hope that the suggestions offered above provide a helpful set of guidelines for best practices in stable isotope mixing models.

\section{Acknowledgements}

The information in this review has been funded in part by the U.S. Environmental Protection Agency (EPA). It has been subjected to the Agency's peer and administrative review and has been approved for publication as an EPA document. Mention of trade names or commercial products does not constitute endorsement or recommendation for use by the EPA. We thank K.A. Hobson and A.L. Bond for constructive comments on an earlier draft.

\section{References}

Adams, T.S., and Sterner, R.W. 2000. The effect of dietary nitrogen content on trophic level ${ }^{15} \mathrm{~N}$ enrichment. Limnol. Oceanogr. 45(3): 601-607. doi:10.4319/ lo.2000.45.3.0601.

Auerswald, K., Wittmer, M.H.O.M., Zazzo, A., Schäufele, R., and Schnyder, H. 2010. Biases in the analysis of stable isotope discrimination in food webs. J. Appl. Ecol. 47: 936-941. doi:10.1111/j.1365-2664.2009.01764.x.

Bearhop, S., Thompson, D.R., Waldron, S., Russell, I.C., Alexander, G., and Furness, R.W. 1999. Stable isotopes indicate the extent of freshwater feeding by cormorants Phalacrocorax carbo shot at inland fisheries in England. J. Appl. Ecol. 36: 75-84. doi:10.1046/j.1365-2664.1999.00378.x.

Ben-David, M., Flynn, R.W., and Schell, D.M. 1997a. Annual and seasonal changes in diets of martens: evidence from stable isotope analysis. Oecologia, 111: 280-291. doi:10.1007/s004420050236.

Ben-David, M., Hanley, T.A., Klein, D.R., and Schell, D.M. 1997b. Seasonal changes 
in diets of coastal and riverine mink: the role of spawning Pacific salmon. Can. J. Zool. 75(5): 803-811. doi:10.1139/z97-102.

Benstead, J.P., March, J.G., Fry, B., Ewel, K.C., and Pringle, C.M. 2006. Testing IsoSource: stable isotope analysis of a tropical fishery with diverse organic matter sources. Ecology, 87(2): 326-333. doi:10.1890/05-0721. PMID:16637358.

Boecklen, W.J., Yarnes, C.T., Cook, B.A., and James, A.C. 2011. On the use of stable isotopes in trophic ecology. Annu. Rev. Ecol. Evol. Syst. 42: 411-440. doi:10. 1146/annurev-ecolsys-102209-144726.

Bond, A.L., and Diamond, A.W. 2011. Recent Bayesian stable-isotope mixing models are highly sensitive to variation in discrimination factors. Ecol. Appl. 21(4): 1017-1023. doi:10.1890/09-2409.1. PMID:21774408.

Budge, S.M., Wang, S.W., Hollmén, T.E., and Wooller, M.J. 2011. Carbon isotopic fractionation in eider adipose tissue varies with fatty acid structure: implications for trophic studies. J. Exp. Biol. 214: 3790-3800. doi:10.1242/jeb. 057596. PMID:22031744.

Bugalho, M.N., Barcia, P., Caldeira, M.C., and Cerdeira, J.O. 2008. Stable isotopes as ecological tracers: an efficient method for assessing the contribution of multiple sources to mixtures. Biogeosciences, 5: 1351-1359. doi:10.5194/bg-51351-2008.

Caut, S., Angulo, E., and Courchamp, F. 2008a. Caution on isotopic model use for analyses of consumer diet. Can. J. Zool. 86(5): 438-445. doi:10.1139/Z08-012.

Caut, S., Angulo, E., and Courchamp, F. 2008b. Discrimination factors $\left(\Delta^{15} \mathrm{~N}\right.$, $\Delta^{13} \mathrm{C}$ ) in an omnivorous consumer: effect of diet isotopic ratio. Funct. Ecol. 22: 255-263. doi:10.1111/j.1365-2435.2007.01360.x.

Caut, S., Angulo, E., and Courchamp, F. 2009. Variation in discrimination factors $\left(\Delta^{15} \mathrm{~N}\right.$ and $\left.\Delta^{13} \mathrm{C}\right)$ : the effect of diet isotopic values and applications for diet reconstruction. J. Appl. Ecol. 46: 443-453. doi:10.1111/j.1365-2664.2009.01620.x.

Cherry, S.G., Derocher, A.E., Hobson, K.A., Stirling, I., and Thiemann, G.W. 2011. Quantifying dietary pathways of proteins and lipids to tissues of a marine predator. J. Appl. Ecol. 48(2): 373-381. doi:10.1111/j.1365-2664.2010.01908.x.

Chiaradia, A., Forero, M.G., McInnes, J.C., and Ramírez, F. 2014. Searching for the true diet of marine predators: incorporating Bayesian priors into stable isotope mixing models. PLoS ONE, 9(3): e92665. doi:10.1371/journal.pone.0092665. PMID: 24667296.

Codron, D., Sponheimer, M., Codron, J., Newton, I., Lanham, J.L., and Clauss, M. 2012. The confounding effects of source isotopic heterogeneity on consumerdiet and tissue-tissue stable isotope relationships. Oecologia, 169: 939-953. doi:10.1007/s00442-012-2274-3. PMID:22349754.

Crawford, K., McDonald, R.A., and Bearhop, S. 2008. Applications of stable isotope techniques to the ecology of mammals. Mammal Rev. 38(1): 87-107. doi:10.1111/j.1365-2907.2008.00120.x.

Dalerum, F., and Angerbjörn, A. 2005. Resolving temporal variation in vertebrate diets using naturally occurring stable isotopes. Oecologia, 144(4): 647658. doi:10.1007/s00442-005-0118-0. PMID:16041545.

DeNiro, M.J., and Epstein, S. 1976. You are what you eat (plus a few permil): the carbon isotope cycle in food chains. Geol. Soc. Am. (Abstracts with Programs), 8: 834-835.

DeNiro, M.J., and Epstein, S. 1978. Influence of diet on the distribution of carbon isotopes in animals. Geochim. Cosmochim. Acta, 42: 495-506. doi:10.1016/ 0016-7037(78)90199-0.

DeNiro, M.J., and Epstein, S. 1981. Influence of diet on the distribution of nitrogen isotopes in animals. Geochim. Cosmochim. Acta, 45: 341-351. doi:10. 1016/0016-7037(81)90244-1.

Edwards, M.A., Derocher, A.E., Hobson, K.A., Branigan, M., and Nagy, J.A. 2011. Fast carnivores and slow herbivores: differential foraging strategies among grizzly bears in the Canadian Arctic. Oecologia, 165(4): 877-889. doi:10.1007| s00442-010-1869-9. PMID:21153738.

Eldridge, P., Cifuentes, L., and Kaldy, J. 2005. Development of a stable-isotope constraint system for estuarine food-web models. Mar. Ecol. Prog. Ser. 303: 73-90. doi:10.3354/meps303073.

Erhardt, E.B., and Bedrick, E.J. 2013. A Bayesian framework for stable isotope mixing models. Environ. Ecol. Stat. 20(3): 377-397. doi:10.1007/s10651-0120224-1.

Evrard, V., Soetaert, K., Heip, C.H.R., Huettel, M., Xenopoulos, M.A., and Middelburg, J.J. 2010. Carbon and nitrogen flows through the benthic food web of a photic subtidal sandy sediment. Mar. Ecol. Prog. Ser. 416: 1-16. doi:10.3354/meps08770.

Evrard, V., Huettel, M., Cook, P.L.M., Soetaert, K., Heip, C.H.R., and Middelburg, J.J. 2012. Importance of phytodetritus and microphytobenthos for heterotrophs in a shallow subtidal sandy sediment. Mar. Ecol. Prog. Ser. 455: 13-31. doi:10.3354/meps09676.

Fernandes, R., Millard, A.R., Brabec, M., Nadeau, M.J., and Grootes, P. 2014. Food reconstruction using isotopic transferred signals (FRUITS): a Bayesian model for diet reconstruction. PLoS ONE, 9(2): e87436. doi:10.1371/journal.pone. 0087436. PMID:24551057.

Florin, S.T., Felicetti, L.A., and Robbins, C.T. 2011. The biological basis for understanding and predicting dietary-induced variation in nitrogen and sulphur isotope ratio discrimination. Funct. Ecol. 25: 519-526. doi:10.1111/j.1365-2435. 2010.01799.x.

Fortin, J.K., Farley, S.D., Rode, K.D., and Robbins, C.T. 2007. Dietary and spatial overlap between sympatric ursids relative to salmon use. Ursus, 18(1): 19-29. doi:10.2192/1537-6176(2007)18[19:DASOBS]2.0.CO;2.

Fox-Dobbs, K., Bump, J.K., Peterson, R.O., Fox, D.L., and Koch, P.L. 2007.
Carnivore-specific stable isotope variables and variation in the foraging ecology of modern and ancient wolf populations: case studies from Isle Royale, Minnesota, and La Brea. Can. J. Zool. 85(4): 458-471. doi:10.1139/Z07-018.

Francis, T.B., Schindler, D.E., Holtgrieve, G.W., Larson, E.R., Scheuerell, M.D., Semmens, B.X., and Ward, E.J. 2011. Habitat structure determines resource use by zooplankton in temperate lakes. Ecol. Lett. 14: 364-372. doi:10.1111/j. 1461-0248.2011.01597.x. PMID:21314881.

Fry, B. 2013. Alternative approaches for solving underdetermined isotope mixing problems. Mar. Ecol. Prog. Ser. 472: 1-13. doi:10.3354/meps10168.

Gannes, L.Z., Martínez del Rio, C., and Koch, P. 1998. Natural abundance variations in stable isotopes and their potential uses in animal physiological ecology. Comp. Biochem. Physiol. A Mol. Integr. Physiol. 119(3): 725-737. doi:10.1016/S1095-6433(98)01016-2.

Gauthier, G., Bety, J., and Hobson, K.A. 2003. Are Greater Snow Geese capital breeders? New evidence from a stable-isotope model. Ecology, 84(12): 32503264. doi:10.1890/02-0613.

Haines, E.B. 1976. Relation between the stable carbon isotope composition of fiddler crabs, plants, and soils in a salt marsh. Limnol. Oceanogr. 21: 880-883. doi:10.4319/10.1976.21.6.0880.

Hall-Aspland, S.A., Hall, A.P., and Rogers, T.L. 2005. A new approach to the solution of the linear mixing model for a single isotope: application to the case of an opportunistic predator. Oecologia, 143: 143-147. doi:10.1007/s00442004-1783-0. PMID:15599768.

Harper, G.A. 2007. Detecting predation of a burrow-nesting seabird by two introduced predators, using stable isotopes, dietary analysis and experimental removals. Wildl. Res. 34(6): 443-453. doi:10.1071/WR07037.

Heady, W.N., and Moore, J.W. 2013. Tissue turnover and stable isotope clocks to quantify resource shifts in anadromous rainbow trout. Oecologia, 172: 21-34. doi:10.1007/s00442-012-2483-9. PMID:23183819.

Hilderbrand, G.V., Farley, S.D., Robbins, C.T., Hanley, T.A., Titus, K., and Servheen, C. 1996. Use of stable isotopes to determine diets of living and extinct bears. Can. J. Zool. 74(11): 2080-2088. doi:10.1139/z96-236.

Hobson, K.A., and Clark, R.G. 1992. Assessing avian diets using stable isotopes I: turnover of ${ }^{13} \mathrm{C}$ in tissues. Condor, 94: 181-188. doi:10.2307/1368807.

Hobson, K.A., and Clark, R.G. 1993. Turnover of ${ }^{13} \mathrm{C}$ in cellular and plasma fractions of blood: implications for nondestructive sampling in avian dietary studies. Auk, 110(3): 638-641. doi:10.2307/4088430.

Hobson, K.A., Piatt, J.F., and Pitocchelli, J. 1994. Using stable isotopes to determine seabird trophic relationships. J. Anim. Ecol. 63: 786-798. doi:10.2307| 5256.

Hopkins, J.B., III, and Ferguson, J.M. 2012. Estimating the diets of animals using stable isotopes and a comprehensive Bayesian mixing model. PLoS ONE, 7(1): e28478. doi:10.1371/journal.pone.0028478. PMID:22235246.

Inger, R., Ruxton, G.D., Newton, J., Colhoun, K., Mackie, K., Robinson, J.A., Jackson, A.L., and Bearhop, S. 2006. Temporal and intrapopulation variation in prey choice of wintering geese determined by stable isotope analysis. J. Anim. Ecol. 75: 1190-1200. doi:10.1111/j.1365-2656.2006.01142.x. PMID:16922855.

Kadoya, T., Osada, Y., and Takimoto, G. 2012. IsoWeb: a Bayesian isotope mixing model for diet analysis of the whole food web. PLoS ONE, 7(7): e41057. doi:10. 1371/journal.pone.0041057. PMID:22848427.

Klaassen, M., Piersma, T., Korthals, H., Dekinga, A., and Dietz, M.W. 2010. Singlepoint isotope measurements in blood cells and plasma to estimate the time since diet switches. Funct. Ecol. 24(4): 796-804. doi:10.1111/j.1365-2435.2010. 01689.x

Koch, P.L., and Phillips, D.L. 2002. Incorporating concentration dependence in stable isotope mixing models: a reply to Robbins, Hilderbrand and Farley (2002). Oecologia, 133: 14-18. doi:10.1007/s00442-002-0977-6. PMID:24599364.

Layman, C.A., Araujo, M.S., Boucek, R., Hammerschlag-Peyer, C.M., Harrison, E., Jud, Z.R., Matich, P., Rosenblatt, A.E., Vaudo, J.J., Yeager, L.A., Post, D.M., and Bearhop, S. 2012. Applying stable isotopes to examine food-web structure: an overview of analytical tools. Biol. Rev. Camb. Philos. Soc. 87(3): 545-562. doi:10.1111/j.1469-185X.2011.00208.x. PMID:22051097.

Lubetkin, S.C., and Simenstad, C.A. 2004. Multi-source mixing models to quantify food web sources and pathways. J. Appl. Ecol. 41(5): 996-1008. doi:10.1111/ j.0021-8901.2004.00957.x.

MacArthur, L.D., Phillips, D.L., Hyndes, G.A., Hanson, C.E., and Vanderklift, M.A. 2011. Habitat surrounding patch reefs influences the diet and nutrition of the western rock lobster. Mar. Ecol. Prog. Ser. 436: 191-205. doi:10.3354/ meps09256.

Martínez del Rio, C., Wolf, N., Carleton, S.A., and Gannes, L.Z. 2009. Isotopic ecology ten years after a call for more laboratory experiments. Biol. Rev. Camb. Philos. Soc. 84: 91-111. doi:10.1111/j.1469-185X.2008.00064.X. PMID: 19046398

McCutchan, J.H., Lewis, W.M., Jr., Kendall, C., and McGrath, C.C. 2003. Variation in trophic shift for stable isotope ratios of carbon, nitrogen, and sulfur. Oikos, 102: 378-390. doi:10.1034/j.1600-0706.2003.12098.x.

McKechnie, A.E. 2004. Stable isotopes: powerful new tools for animal ecologists. S. Afr. J. Sci. 100(3-4): 131-134

Middelburg, J.J. 2014. Stable isotopes dissect aquatic food webs from the top to the bottom. Biogeosciences, 11: 2357-2371. doi:10.5194/bg-11-2357-2014.

Miron, M.L.L., Herrera, M.L.G., Ramirez, P.N., and Hobson, K.A. 2006. Effect of diet quality on carbon and nitrogen turnover and isotropic discrimination in 
blood of a New World nectarivorous bat. J. Exp. Biol. 209: 541-548. doi:10. 1242/jeb.02016. PMID:16424104.

Moore, J.W., and Semmens, B.X. 2008. Incorporating uncertainty and prior information into stable isotope mixing models. Ecol. Lett. 11: 470-480. doi:10. 1111/j.1461-0248.2008.01163.x. PMID:18294213.

Newsome, S.D., Phillips, D.L., Culleton, B.J., Guilderson, T.P., and Koch, P.L. 2004. Dietary reconstruction of an early to middle Holocene human population from the central California coast: insights from advanced stable isotope mixing models. J. Archaeol. Sci. 31: 1101-1115. doi:10.1016/j.jas.2004.02.001.

Newsome, S.D., Bentall, G.B., Tinker, M.T., Oftedal, O.T., Ralls, K., Estes, J.A., and Fogel, M.L. 2010. Variation in $\delta^{13} \mathrm{C}$ and $\delta^{15} \mathrm{~N}$ diet-vibrissae trophic discrimination factors in a wild population of California sea otters. Ecol. Appl. 20(6): 1744-1752. doi:10.1890/09-1502.1. PMID:20945772.

Olive, P.J.W., Pinnegar, J.K., Polunin, N.V.C., Richards, G., and Welch, R. 2003. Isotrophic trophic-step fractionation: a dynamic equilibrium. J. Anim. Ecol. 72: 608-617. doi:10.1046/j.1365-2656.2003.00730.x.

Pacella, S.R., Lebreton, B., Richard, P., Phillips, D., DeWitt, T.H., and Niquil, N. 2013. Incorporation of diet information derived from Bayesian stable isotope mixing models into mass-balanced marine ecosystem models: a case study from the Marennes-Oléron Estuary, France. Ecol. Model. 267: 127-137. doi:10. 1016/j.ecolmodel.2013.07.018.

Painter, M.L., Chambers, C.L., Siders, M., Doucett, R.R., Whitaker, J.O., Jr., and Phillips, D.L. 2009. Diet of spotted bats (Euderma maculatum) in Arizona as indicated by fecal analysis and stable isotopes. Can. J. Zool. 87(10): 865-875. doi:10.1139/Z09-075.

Parnell, A.C., Inger, R., Bearhop, S., and Jackson, A.L. 2010. Source partitioning using stable isotopes: coping with too much variation. PLoS ONE, 5(3): e9672. doi:10.1371/journal.pone.0009672. PMID:20300637.

Parnell, A.C., Phillips, D.L., Bearhop, S., Semmens, B.X., Ward, E.J., Moore, J.W., Jackson, A.L., Grey, J., Kelly, D., and Inger, R. 2013. Bayesian stable isotope mixing models. Environmetrics, 24: 387-399. doi:10.1002/env.2221.

Perga, M.-E., and Grey, J. 2010. Laboratory measures of isotope discrimination factors: comments on Caut, Angulo and Courchamp (2008, 2009). J. Appl. Ecol. 47: 942-947. doi:10.1111/j.1365-2664.2009.01730.x.

Peterson, B.J., and Fry, B. 1987. Stable isotopes in ecosystem studies. Annu. Rev. Ecol. Syst. 18: 293-320. doi:10.1146/annurev.es.18.110187.001453.

Phillips, D.L. 2012. Converting isotope values to diet composition: the use of mixing models. J. Mammal. 93(2): 342-352. doi:10.1644/11-MAMM-S-158.1.

Phillips, D.L., and Eldridge, P.M. 2006. Estimating the timing of diet shifts using stable isotopes. Oecologia, 147(2): 195-203. doi:10.1007/s00442-005-0292-0. PMID:16341714

Phillips, D.L., and Gregg, J.W. 2001a. Uncertainty in source partitioning using stable isotopes. Oecologia, 127: 171-179. doi:10.1007/s004420000578. PMID: 24577646.

Phillips, D.L., and Gregg, J.W. 2001b. Uncertainty in source partitioning using stable isotopes (erratum). Oecologia, 128: 304. doi:10.1007/s004420100723.

Phillips, D.L., and Gregg, J.W. 2003. Source partitioning using stable isotopes: coping with too many sources. Oecologia, 136: 261-269. doi:10.1007/s00442003-1218-3. PMID:12759813.

Phillips, D.L., and Koch, P.L. 2002. Incorporating concentration dependence in stable isotope mixing models. Oecologia, 130: 114-125. doi:10.1007/ s004420100786.

Phillips, D.L., Newsome, S.D., and Gregg, J.W. 2005. Combining sources in stable isotope mixing models: alternative methods. Oecologia, 144: 520-527. doi: 10.1007/s00442-004-1816-8. PMID:15711995.

Phillips, D.L., Schuur, E.A.G., Brooks, J.R., Ben-David, M., and Fry, B. 2006. When isotopes aren't enough: using additional information to constrain mixing problems. In Conference Abstracts and Programme of the 5th International Conference on Applications of Stable Isotope Techniques to Ecological Studies, Belfast, Northern Ireland, 13-18 August 2006. Queens University Belfast, Belfast, Northern Ireland. p. 59.

Radtke, R.L., Showers, W., Moksness, E., and Lenz, P. 1996. Environmental information stored in otoliths: insights from stable isotopes. Mar. Biol. (Berl.), 127: 161-170. doi:10.1007/BF00993656.

Ramírez-Hernández, G., and Herrera, M., L.G. 2010. Nutritional importance of seeds and arthropods to painted spiny pocket mice (Lyomis pictus): the effects of season and forest degradation. Can. J. Zool. 88(12): 1226-1234. doi:10.1139/ Z10-087.

Reid, D.J., Quinn, G.P., Lake, P.S., and Reich, P. 2008. Terrestrial detritus supports the food webs in lowland intermittent streams of south-eastern Australia: a stable isotope study. Freshw. Biol. 53: 2036-2050. doi:10.1111/j.1365-2427. 2008.02025.x.

Robbins, C.T., Felicetti, L.A., and Sponheimer, M. 2005. The effect of dietary protein quality on nitrogen isotope discrimination in mammals and birds. Oecologia, 144: 534-540. doi:10.1007/s00442-005-0021-8. PMID:15800751.

Rosing, M.N., Ben-David, M., and Barry, R.P. 1998. Analysis of stable isotope data: a K nearest-neighbors randomization test. J. Wildl. Manage. 62(1): 380-388. doi: $10.2307 / 3802302$.

Rutz, C., Bluff, L.A., Reed, N., Troscianko, J., Newton, J., Inger, R., Kacelnik, A., and Bearhop, S. 2010. The ecological significance of tool use in New Caledonian crows. Science, 329(5998): 1523-1526. doi:10.1126/science.1192053. PMID: 20847272.

Semmens, B.X., Ward, E.J., Moore, J.W., and Darimont, C.T. 2009. Quantifying inter- and intra-population niche variability using hierarchical Bayesian stable isotope mixing models. PLoS ONE, 4(7): e6187. doi:10.1371/journal.pone. 0006187. PMID:19587790.

Semmens, B.X., Ward, E.J., Parnell, A.C., Phillips, D.L., Bearhop, S., Inger, R., Jackson, A.L., and Moore, J.W. 2013. Statistical basis and outputs of stable isotope mixing models: comment on Fry (2013). Mar. Ecol. Prog. Ser. 490: 285-289. doi:10.3354/meps10535.

Sinisalo, T., Valtonen, E.T., Helle, E., and Jones, R.I. 2006. Combining stable isotope and intestinal parasite information to evaluate dietary differences between individual ringed seals (Phoca hispida botnica). Can. J. Zool. 84(6): 823-831. doi:10.1139/z06-067.

Smith, J.A., Mazumder, D., Suthers, I.M., and Taylor, M.D. 2013. To fit or not to fit: evaluating stable isotope mixing models using simulated mixing polygons. Methods Ecol. Evol. 4(7): 612-618. doi:10.1111/2041-210X.12048.

Spence, K.O., and Rosenheim, J.A. 2005. Isotopic enrichment in herbivorous insects: a comparative field-based study of variation. Oecologia, 146: 89-97. doi:10.1007/s00442-005-0170-9. PMID:16012818.

Stock, B.C., and Semmens, B.X. 2013. MixSIAR GUI user manual: version 1.0. Available from http://conserver.iugo-cafe.org/user/brice.semmens/MixSIAR.

Tieszen, L.L., Boutton, T.W., Tesdahl, K.G., and Slade, N.A. 1983. Fractionation and turnover of stable carbon isotopes in animal tissues: implications for $\delta^{13} \mathrm{C}$ analysis of diet. Oecologia, 57: 32-37. doi:10.1007/BF00379558.

Van den Meersche, K., Van Rijswijk, P., Soetaert, K., and Middelburg, J.J. 2009. Autochthonous and allochthonous contributions to mesozooplankton diet in a tidal river and estuary: integrating carbon isotope and fatty acid constraints. Limnol. Oceanogr. 54: 62-74. doi:10.4319/1o.2009.54.1.0062.

Vanderklift, M.A., and Ponsard, S. 2003. Sources of variation in consumer-diet $\delta^{15} \mathrm{~N}$ enrichment: a meta-analysis. Oecologia, 136: 169-182. doi:10.1007/s00442003-1270-z. PMID:12802678.

Vaslet, A., France, C., Phillips, D.L., Feller, I.C., and Baldwin, C.C. 2011. Stableisotope analyses reveal the importance of seagrass beds as feeding areas for juveniles of the speckled worm eel Myrophis punctatus (Teleostei: Ophichthidae) in Florida. J. Fish Biol. 79: 692-706. doi:10.1111/j.1095-8649.2011.03052.x. PMID:21884107.

Vezina, A., and Platt, T. 1988. Food web dynamics in the ocean. 1. Best-estimates of flow networks using inverse methods. Mar. Ecol. Prog. Ser. 42: 269-287.

Votier, S.C., Bearhop, S., MacCormick, A., Ratcliffe, N., and Furness, R.W. 2003. Assessing the diet of great skuas, Catharacta skua, using five different techniques. Polar Biol. 26: 20-26. doi:10.1007/s00300-002-0446-z.

Ward, E.J., Semmens, B.X., and Schindler, D.E. 2010. Including source uncertainty and prior information in the analysis of stable isotope mixing models. Environ. Sci. Technol. 44: 4645-4650. doi:10.1021/es100053v. PMID:20496928.

Ward, E.J., Semmens, B.X., Phillips, D.L., Moore, J.W., and Bouwes, N. 2011. A quantitative approach to combine sources in stable isotope mixing models. Ecosphere, 2(2): art19. doi:10.1890/es10-00190.1.

Webb, S.C., Hedges, R.E.M., and Simpson, S.J. 1998. Diet quality influences the $\delta^{13} \mathrm{C}$ and $\delta^{15} \mathrm{~N}$ of locusts and their biochemical components. J. Exp. Biol. 201: 2903-2911. PMID:9739072.

Willson, J.D., Winne, C.T., Pilgrim, M.A., Romanek, C.S., and Gibbons, J.W. $2010 a$. Seasonal variation in terrestrial resource subsidies influences trophic niche width and overlap in two aquatic snake species: a stable isotope approach. Oikos, 119: 1161-1171. doi:10.1111/j.1600-0706.2009.17939.x.

Wilson, R.M., Chanton, J., Lewis, F.G., and Nowacek, D. 2010b. Concentrationdependent stable isotope analysis of consumers in the upper reaches of a freshwater-dominated estuary: Apalachicola Bay, FL, USA. Estuaries and Coasts, 33: 1406-1419.

Wolf, N., Carleton, S.A., and Martínez del Rio, C. 2009. Ten years of experimental animal isotopic ecology. Funct. Ecol. 23: 17-26. doi:10.1111/j.1365-2435.2009. 01529.x.

Yeakel, J.D., Novak, M., Guimarães, P.R., Dominy, N.J., Koch, P.L., Ward, E.J., Moore, J.W., and Semmens, B.X. 2011. Merging resource availability with isotope mixing models: the role of neutral interaction assumptions. PLoS ONE, 6(7): e22015. doi:10.1371/journal.pone.0022015. PMID:21760944. 